\title{
ESR1 hotspot mutations in endometrial stromal sarcomas may confer hormonal resistance
}

Departments of ${ }^{1}$ Surgery, ${ }^{2}$ Pathology and ${ }^{3}$ Medicine, Memorial Sloan Kettering Cancer Center, New York, NY, USA

\section{BACKGROUND}

- Endometrial stromal sarcomas are a rare subset of uterine mesenchymal tumors, accounting for $0.2 \%$ of all uterine malignancies.

- Low-grade endometrial stromal sarcomas (LGESS) may show high-grade morphology in primary or recurrent tumors.

- These lesions are classified as high-grade endometrial stromal sarcomas (HGESS), which in general are more aggressive and have higher rates of resistance to endocrine therapy than LGESS.

- The pathogenesis of hormonal resistance in these tumors has yet to be defined.

\section{AlMS}

- Characterize the mutational profiles of primary LGESS and associated recurrences with high-grade morphology following endocrine therapy.

\section{METHODS}

- DNA from tumor and normal tissues was extracted from all samples from case 1 and case 2 , summarized in Table 1.

- DNA was subjected to our institutional massively parallel sequencing platform targeting 468 cancer genes (MSKIMPACT).

- RNA from each case was also evaluated for the presence of gene fusions using ARCHER FusionPlex.

- Sequencing data were analyzed using validated bioinformatics algorithms.

\section{RESULTS}

- Both patients received at least two lines of hormonal suppressive therapy including letrozole and megestrol.

- ARCHER FusionPlex analysis revealed that cases 1 and 2 harbored JAZF1-PHF1 and EPC1-PHF1 fusions, respectively.

- Targeted massively parallel sequencing revealed that these lesions harbored few non-synonymous somatic mutations.

- The primary LGESS and the two HGESS recurrences of case 1 shared a KDM5C frame-shift mutation; however in the second HGESS recurrence post endocrine treatment, a clonal STK40 (R128W) mutation and an ESR1 (Y537S) hotspot mutation were detected.

- Both LGESS and HGESS recurrences of case 2 harbored an ESR1 (Y537S) hotspot mutation. In addition, an HRAS (Q61R) hotspot mutation restricted to the recurrent LGESS was identified.

- ESR1 hotspot mutations have been shown to play a role in acquired endocrine therapy resistance in breast cancer.

\begin{tabular}{|c|c|c|c|}
\hline Year & Sample ID & Pathology & Treatment \\
\hline \multicolumn{4}{|c|}{ Case 1 - JAZF1-PHF1 fusion } \\
\hline 2006 & ESR1-1-A & $\begin{array}{l}\text { Primary: } \\
\text { LG-ESS, ER+ PR+ }\end{array}$ & Megestrol \\
\hline 2012 & $\mathrm{~N} / \mathrm{A}$ & $\begin{array}{l}\text { Recurrence \#1: } \\
\text { HG-ESS, ER+ PR+ }\end{array}$ & Arimidex \\
\hline 2015 & ESR1-1-B & $\begin{array}{l}\text { Recurrence \#2: } \\
\text { HG-ESS, ER+ PR+ }\end{array}$ & Letrazole \\
\hline 2017 & ESR1-1C & $\begin{array}{l}\text { Recurrence \#3: } \\
\text { HG-ESS, PR diffuse+; ER } \\
\text { weak +; ESR1 Mutation + }\end{array}$ & Fulvestrant \\
\hline \multicolumn{4}{|c|}{ Case 2 - EPC1-PHF1 fusion } \\
\hline 2013 & $\mathrm{~N} / \mathrm{A}$ & $\begin{array}{l}\text { Primary: } \\
\text { LG-ESS, ER+ PR+ }\end{array}$ & $\begin{array}{l}\text { Letrazole } \rightarrow \\
\text { Megestrol } \\
\rightarrow \text { Docetaxol/ge } \\
\text { mcitabine }\end{array}$ \\
\hline 2016 & ESR1-2 & $\begin{array}{l}\text { Recurrence \#1: } \\
\text { LG-ESS, ER+ PR+, } \\
\text { ESR1 Mutation + }\end{array}$ & \\
\hline 2017 & ESR1-4 & $\begin{array}{l}\text { Recurrence \#2: } \\
\text { HGESS ,ER+ PR+, ESR1 } \\
\text { Mutation + }\end{array}$ & $\begin{array}{l}\text { Doxorubicin } \rightarrow \\
\text { Fulvestrant }\end{array}$ \\
\hline
\end{tabular}

\section{CASE 1}

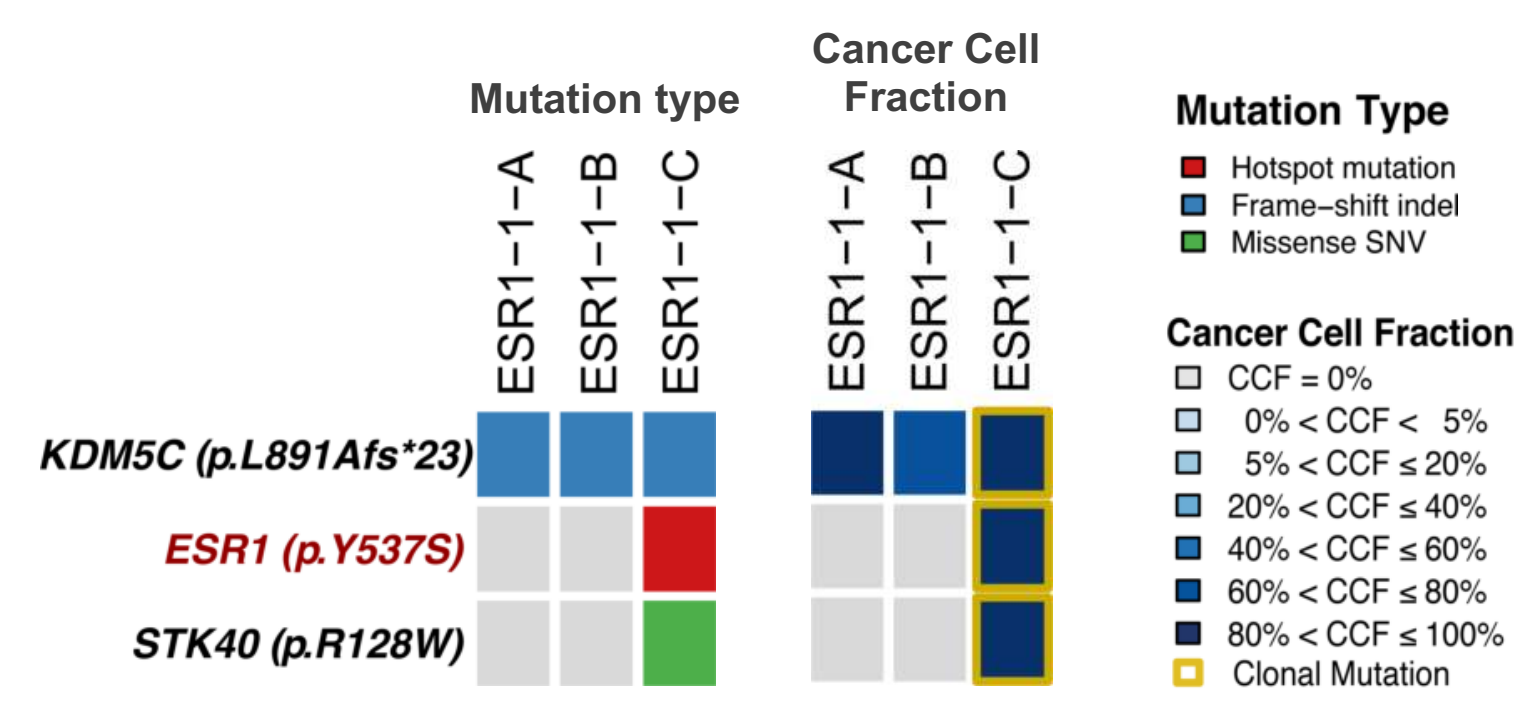

Figure 1: Repertoire of somatic mutations in endometrial stromal sarcoma case 1. (Left) Non-synonymous somatic mutations identified in the primary tumor $(A)$, the recurrence 9 years (B) and 11 years (C) after initial diagnosis. (Right) Cancer cell fractions of the mutations identified, color-coded according to the legend. Note the clonal ESR1 hotspot mutation is present only in last recurrence.

CASE 2

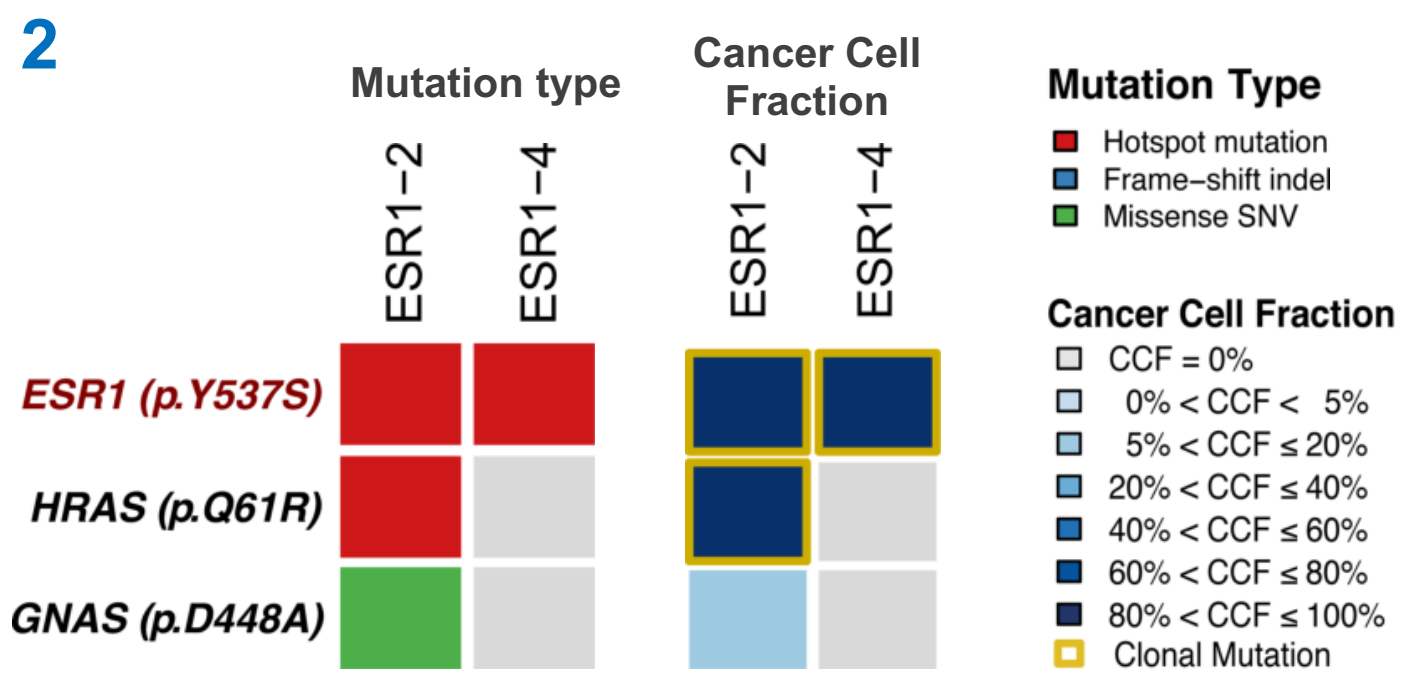

Figure 2: Repertoire of somatic mutations in endometrial stromal sarcoma case2. (Left) Non-synonymous somatic mutations identified in the recurrences 3 years (2) and 4 years (4) after initial diagnosis. (Right) Cancer cell fractions of the mutations identified, color-coded according to the legend. Note the clonal ESR1 hotspot mutation was present in all recurrences. Material from the primary tumor was not available for analysis.

\section{CONCLUSION}

Our findings suggest that ESR1 hotspot mutations in LGESS, either pre-existing or acquired, may be associated with endocrine resistance and high-grade transformation in ESS. 